\title{
Virulence of Japanese Encephalitis Virus Genotypes I and III, Taiwan
}

\author{
Yi-Chin Fan, ${ }^{1}$ Jen-Wei Lin, ${ }^{1}$ Shu-Ying Liao, \\ Jo-Mei Chen, Yi-Ying Chen, Hsien-Chung Chiu, \\ Chen-Chang Shih, Chi-Ming Chen, \\ Ruey-Yi Chang, Chwan-Chuen King, \\ Wei-June Chen, Yi-Ting Ko, Chao-Chin Chang, \\ Shyan-Song Chiou
}

The virulence of genotype I (GI) Japanese encephalitis virus (JEV) is under debate. We investigated differences in the virulence of GI and GIII JEV by calculating asymptomatic ratios based on serologic studies during GI- and GIII-JEV endemic periods. The results suggested equal virulence of GI and GIII JEV among humans.

$\mathrm{J}$ apanese encephalitis virus (JEV), a mosquitoborne flavivirus, causes Japanese encephalitis (JE). This virus has been reported in Southeast Asia and Western Pacific regions since it emerged during the 1870s in Japan (1). JEVs are divided into 5 genotypes on the basis of envelope structural protein genes for phylogenetic reconstruction. JEV genotype III (GIII) has been the most widely distributed in the temperate zone and is most frequently associated with JEV outbreaks in Asia. JEV genotype I (GI) originated in Indonesia and circulated in Thailand and Cambodia during the 1970s (1). Dominance of GIII was replaced by GI during 1992-2001 in Japan, Korea, Thailand, and Vietnam (1).

In Japan, the confirmed case incidence of JEV suddenly decreased from 20-50 cases each year during 1980 1990 to $<10$ cases after 1992 (2). This decrease may be related to implementation of JEV vaccine in Japan but also to less virulent GI JE viruses circulating there (3-6). A similar decrease was not seen in the other countries where genotype replacement had also occurred in recent years (7). In Taiwan, JEV GI was first detected in 2008 and became the island-wide dominant circulating genotype

Author affiliations: National Chung Hsing University, Taichung, Taiwan (Y.-C. Fan, J.-W. Lin, S.-Y. Liao, J.-M. Chen, Y.-Y. Chen, C.-M. Chen, Y.-T. Ko, C.-C. Chang, S.-S. Chiou); National Defense Medical Center, Taipei, Taiwan (H.-C. Chiu); Tri-Service General Hospital (H.-C. Chiu); Taiwan Mennonite Christian Hospital, Hualien, Taiwan (C.-C. Shih); Tungs' Taichung MetroHarbor Hospital, Taichung (C.-M. Chen); National Dong Hwa University, Hualien (R.-Y. Chang); National Taiwan University, Taipei (C.-C. King); Chang Gung University, Taoyuan, Taiwan (W.-J. Chen)

DOI: https://doi.org/10.3201/eid2311.161443 within a year $(8,9)$, which provided an excellent opportunity to study the transmission dynamics and pathogenicity of these 2 JEV genotypes.

A mouse model showed that the pathogenic potential is similar among different JEV genotypes (10). However, the pathogenic difference between GI and GIII virus infections among humans remains unclear. Endy et al. reported that the proportion of asymptomatic infected persons among total infected persons (asymptomatic ratio) is an excellent indicator for estimating virulence or pathogenicity of dengue virus infections among humans (11). We used the asymptomatic ratio method for a study to determine if GI JEV is associated with lower virulence than GIII JEV among humans in Taiwan.

\section{The Study}

JEVs were identified in 6 locations in Taiwan during 19942012 (online Technical Appendix Figure, panel A, https:// wwwnc.cdc.gov/EID/article/23/11/16-1443-Techapp1. pdf). GIII viruses were the only known circulating JEVs in Taiwan before 2009 (online Technical Appendix Figure, panel B). A genotype shift was complete by 2009, and since then, all JEV isolates in Taiwan have evolved from GI viruses (8). To investigate differences in the virulence of GIII and GI viruses in human infections, we conducted a subcohort and cross-sectional combined study to determine the JEV asymptomatic infection ratio. We used serum panels collected during the GIII JEV endemic period (1994-2000 [12,13]) and during the GI JEV endemic period (2010-2012).

The institutional review boards of the Mennonite Christian Hospital and the Tungs' Taichung Metroharbor Hospital reviewed and approved clinical protocols for the serum sample collection. Approximately $10 \%$ of total specimens were paired serum samples. We used the plaque reduction neutralization test (PRNT) and IgM antibodycapture ELISA (MAC-ELISA) to determine the infection status of each serum specimen (14). We tested serum panels collected before and after 2009 by using MAC-ELISA and PRNT and used viral antigens and viruses derived from the GIII-T1P1 and GI-YL2009-4 strains, respectively.

We further tested all neutralizing and IgM antibodypositive specimens by using GI YL2009-4, GIII T1P1, and dengue virus 2 (DENV-2) viral antigens to determine the genotype-specific infection status and to exclude false-

${ }^{1}$ These authors contributed equally to this article. 
Table 1. Descriptive characteristics of populations for study of virulence of JEV genotypes I and III, Taiwan*

\begin{tabular}{|c|c|c|c|c|c|c|c|c|c|}
\hline \multirow[b]{2}{*}{ Characteristic } & \multicolumn{8}{|c|}{ Region } & \multirow[b]{2}{*}{$\mathrm{p}$ value } \\
\hline & Changhua & Taipei & Pingtung & Miaoli & Taichung & Hualien & Taichung & Hualien & \\
\hline Year & 1994 & 1995 & 1999 & 2000 & 2010 & 2010 & 2012 & 2012 & ND \\
\hline Circulating JEV & GIII & GIII & GIII & GIII & $\mathrm{GI}$ & $\mathrm{GI}$ & GI & $\mathrm{GI}$ & ND \\
\hline No. participants & 795 & 886 & 571 & 274 & 510 & 754 & 527 & 300 & ND \\
\hline No. (\%) vaccinated & 36 & 41 & 41 & 33 & 48 & 48 & 49 & 46 & $<0.05$ \\
\hline Average age, ył & 42.8 & 40.9 & 47.1 & 51.3 & 49.6 & 48.1 & 52.0 & 49.2 & $<0.05$ \\
\hline Male sex, \% & 45 & 52 & 47 & 54 & 50 & 48 & 52 & 49 & $>0.05$ \\
\hline
\end{tabular}

positive results possibly caused by DENV infection. We used SAS version 9.4 (SAS Institute Inc., Cary, NC, USA) for statistical analyses.

We collected 5,557 specimens from 4,617 participants (Table 1 ). The average participant age by year ranged from 40.9 to 52.0 years $(p<0.05)$; overall, $49.6 \%$ of participants were male and $50.4 \%$ female $(\mathrm{p}>0.05)$. The proportion of persons receiving JEV vaccinations increased over time from $33 \%$ to $49 \%(\mathrm{p}<0.05)$.

The positivity rate for neutralizing antibody, elicited by natural infection or immunization in the past, differed significantly, ranging from $58 \%$ to $75 \%$ among the 8 serum panels $(p<0.05)$ (Table 2). A JEV infection that had been acquired recently was indicated by the presence of IgM among the seronegative population, seroconversion of the neutralizing antibody, and $\mathrm{a} \geq 4$-fold increase in the neutralizing antibody titer among the seropositive population. For the 8 serum panels, the IgM positivity rate ranged from $0.90 \%$ to $4.91 \%(\mathrm{p}<0.05)$, and the proportion of seroconversion and $\mathrm{a} \geq 4$-fold increase in the neutralizing antibody titer ranged from $0 \%$ to $1.37 \%(\mathrm{p}>0.05)$. The incidence rate of JEV infection ranged from $1.83 \%$ to $5.49 \%(\mathrm{p}<0.05)$ in the 8 serum panels.

We calculated the asymptomatic ratio by dividing the number of confirmed JE cases by the number of JEV infection cases. The number of confirmed JE cases (Table 2) was obtained from the CDC National Infectious Disease Statistics System, Taiwan (https://nidss.cdc.gov.tw/en/Default.aspx), which reported 1-4 cases/year in the regions from which the 8 serum panels were collected (Table 2). The number of JEV infection cases, calculated by multiplying the total population by the incidence of JEV infection, ranged from 10,243 to 53,657 in the 8 serum panels. The asymptomatic ratios $(95 \% \mathrm{CI})$ for GIII virus infection were $1: 6,640(1: 5,102-1: 8,000)$ for Changhua County in 1994; $1: 17,886(1: 15,408-1: 21,322)$ for Taipei City in 1995; $1: 8,779(1: 8,000-1: 9,709)$ for Pingtung County in 1999; and 1:10,243 $(1: 8,065-1: 13,947)$, for Miaoli County in 2000 . The asymptomatic ratios for GI virus infection were 1:7,029 (1:6,329-1:7,874) for Taichung City and 1:6,063

\begin{tabular}{|c|c|c|c|c|c|c|c|c|c|}
\hline \multirow[b]{2}{*}{ Characteristic } & \multicolumn{8}{|c|}{ Region } & \multirow[b]{2}{*}{$\mathrm{p}$ value } \\
\hline & Changhua & Taipei & Pingtung & Miaoli & Taichung & Hualien & Taichung & Hualien & \\
\hline Year & 1994 & 1995 & 1999 & 2000 & 2010 & 2010 & 2012 & 2012 & ND \\
\hline $\begin{array}{l}\text { No. specimens } \\
\text { (incidence of infection) }\end{array}$ & $966(171)$ & $974(88)$ & $638(67)$ & $411(137)$ & $656(146)$ & $905(151)$ & $632(105)$ & $375(75)$ & ND \\
\hline NT positive, $\%$ & 62 & 69 & 60 & 58 & 65 & 75 & 72 & 66 & $<0.05$ \\
\hline IgM positive, \% (A) & 4.91 & 0.90 & 1.93 & 1.10 & 0.98 & 2.25 & 3.23 & 3.67 & $<0.05$ \\
\hline $\begin{array}{l}\text { Seroconversion + } \\
\geq 4 \text {-fold increase in } \\
\text { NT titer, \%‡ (B) }\end{array}$ & 0.58 & 1.13 & 0 & 0.73 & 1.37 & 1.32 & 0.95 & 1.33 & $>0.05$ \\
\hline $\begin{array}{l}\text { Incidence of infection, \% } \\
(C=A+B)\end{array}$ & 5.49 & 2.03 & 1.93 & 1.83 & 2.35 & 3.57 & 4.18 & 5.00 & $<0.05$ \\
\hline Population§ (D) & 483,766 & $2,643,221$ & 909,778 & 559,703 & 598,186 & 339,659 & 593,780 & 337,382 & ND \\
\hline $\begin{array}{l}\text { Predicted no. infections } \\
(E=C \times D)\end{array}$ & 26,559 & 53,657 & 17,559 & 10,243 & 14,057 & 12,126 & 24,820 & 16,869 & ND \\
\hline Confirmed cases $(\mathrm{F}) \mathbb{I}$ & 4 & 3 & 2 & 1 & 2 & 2 & 2 & 2 & ND \\
\hline $\begin{array}{l}\text { Asymptomatic ratio } \\
(\mathrm{G}=\mathrm{F} / \mathrm{E})\end{array}$ & $1 / 6,640$ & $1 / 17,886$ & $1 / 8,779$ & $1 / 10,243$ & $1 / 7,029$ & $1 / 6,063$ & $1 / 12,410$ & $1 / 8,435$ & $>0.05$ \\
\hline $\begin{array}{l}\text { Asymptomatic ratio, } \\
95 \% \mathrm{Cl}\end{array}$ & $\begin{array}{c}1 / 5,102- \\
1 / 8,000\end{array}$ & $\begin{array}{c}1 / 15,408- \\
1 / 21,322\end{array}$ & $\begin{array}{c}1 / 8,000- \\
1 / 9,709\end{array}$ & $\begin{array}{l}1 / 8,065- \\
1 / 13,947\end{array}$ & $\begin{array}{c}1 / 6,329- \\
1 / 7,874\end{array}$ & $\begin{array}{c}1 / 5,348- \\
1 / 6,993\end{array}$ & $\begin{array}{c}1 / 10,846- \\
1 / 14,493\end{array}$ & $\begin{array}{l}1 / 7,299 \\
1 / 10,010\end{array}$ & ND \\
\hline
\end{tabular}

*Serum samples were collected after the Japanese encephalitis season (May-September); multiple serum samples were collected from some participants. JEV, Japanese encephalitis virus; ND, no data; NT, neutralizing antibody.

†Analyzed by using one-way analysis of variance.

†Among the IgM-negative population, JEV infection was estimated by the observation of an increase in the NT titer, including seroconversion and $\geq 4$-fold

increase in the NT titer among subjects with multiple serum samples.

§In Taichung, only residents of the districts around the serum-collecting hospital were included.

IAccording to the official report of the Taiwan Centers for Disease Control. 
$(1: 5,348-1: 6,993)$ for Hualien County in 2010; ratios were 1:12,410 $(1: 10,846-1: 14,493)$ for Taichung City and 1:8,435 (1:7,229-1:10,010) for Hualien County in 2012.

We applied the log-linear Poisson regression model to adjust the asymptomatic ratio by the number of patients who had encephalitis and were infected by other pathogens, and also by age, sex, and vaccination status (online Technical Appendix Table) (15). The results revealed that non-JEV-specific encephalitis symptoms (fever, headache, convulsion, and seizure) (intercept, $\mathrm{p}<0.05$ ) influenced the calculation of asymptomatic ratios but not age, sex, or vaccination status ( $\mathrm{p}>0.05)$.

We calculated the overall GI JEV- and GIII JEV-specific asymptomatic ratios by using the adjusted asymptomatic ratios of the 8 serum panels collected during the GI JEVand GIII JEV-endemic periods (Figure). The GI-specific asymptomatic ratio was $1: 15,378(1: 6,168-1: 24,588)$ and the GIII-specific ratio was $1: 18,842(1: 6,624-1: 30,260)$; these ratios were not significantly different $(\mathrm{p}>0.05)$.

\section{Conclusions}

The possible effects of JEV genotype replacement remain unclear, particularly in terms of disease burden, virulence, vaccine efficacy, and policy decisions. In this study, we combined the IgM seropositivity rate, the proportion of seroconversion, and paired samples displaying a $\geq 4$-fold increase in the neutralizing antibody titer to calculate incidence of the infection (Table 2). The results showed that the incidence of JEV infection fluctuated over years and in different regions in Taiwan. Nevertheless, genotype replacement had no significant effect on this fluctuation (GI:GIII $=3.78 \pm 1.25: 2.82 \pm 3.18 ; \mathrm{p}>0.05)$.

The dramatic decline observed in the number of clinical JE cases after the genotype replacement from GIII to GI

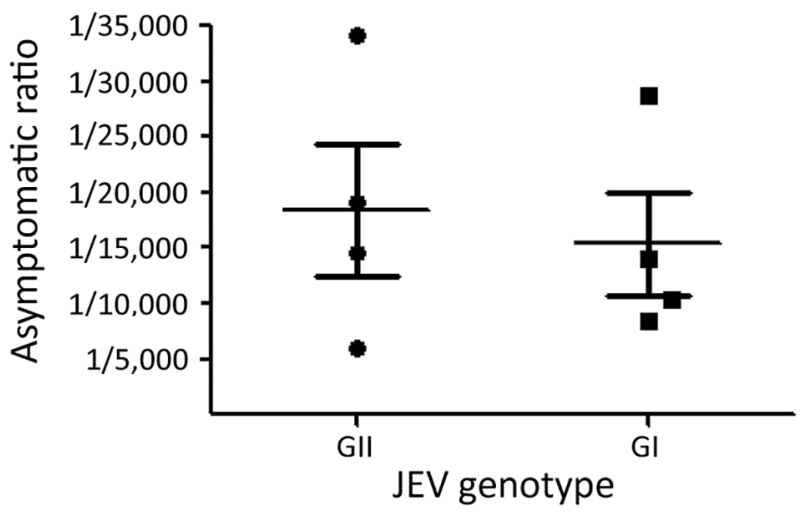

Figure. JEV genotype-specific asymptomatic ratios for 8 serum panels collected during the GIII- and Gl-endemic periods (19942000 and 2010-2012) in Taiwan. The adjusted asymptomatic ratios estimated from genotype-representing populations were included to calculate JEV genotype-specific asymptomatic ratios. Horizontal lines indicate mean; error bars indicate SEM. JEV, Japanese encephalitis virus. in Japan suggested that GI viruses were less virulent than GIII viruses (3-6). However, we found that the asymptomatic ratio of GI and GIII JEV infections was similar, indicating equal virulence of GIII and GI JEVs. These results were also supported by the mouse virulence and neurovirulence experiments and disease burden estimation (10).

\section{Acknowledgments}

We thank the study subjects and the nurses of the Mennonite Christian Hospital and the Tungs' Taichung MetroHarbor Hospital for their assistance with the study subjects and specimen processing.

This work was supported by the Ministry of Science and Technology, R.O.C. (research grant NSC 102-2321-B-005-019).

Dr. Fan is a postdoctoral researcher at Graduate Institute of Microbiology and Public Health, National Chung Hsing University, Taiwan. Her research interests focus on the host tropism of flavivirus and the underlying mechanism(s) of genotype replacement of Japanese encephalitis virus.

\section{References}

1. Pan XL, Liu H, Wang HY, Fu SH, Liu HZ, Zhang HL, et al. Emergence of genotype I of Japanese encephalitis virus as the dominant genotype in Asia. J Virol. 2011;85:9847-53. http://dx.doi.org/10.1128/JVI.00825-11

2. Arai S, Matsunaga Y, Takasaki T, Tanaka-Taya K, Taniguchi K, Okabe N, et al.; Vaccine Preventable Diseases Surveillance Program of Japan. Japanese encephalitis: surveillance and elimination effort in Japan from 1982 to 2004. Jpn J Infect Dis. 2008;61:333-8.

3. Nerome R, Tajima S, Takasaki T, Yoshida T, Kotaki A, Lim CK, et al. Molecular epidemiological analyses of Japanese encephalitis virus isolates from swine in Japan from 2002 to 2004. J Gen Virol. 2007;88:2762-8. http://dx.doi.org/10.1099/vir.0.82941-0

4. Takegami T, Ishak H, Miyamoto C, Shirai Y, Kamimura K. Isolation and molecular comparison of Japanese encephalitis virus in Ishikawa, Japan. Jpn J Infect Dis. 2000;53:178-9.

5. Han N, Adams J, Chen P, Guo ZY, Zhong XF, Fang W, et al. Comparison of genotypes I and III in Japanese encephalitis virus reveals distinct differences in their genetic and host diversity. J Virol. 2014;88:11469-79. http://dx.doi.org/10.1128/JVI.02050-14

6. Konishi E, Kitai Y, Tabei Y, Nishimura K, Harada S. Natural Japanese encephalitis virus infection among humans in west and east Japan shows the need to continue a vaccination program. Vaccine. 2010;28:2664-70. http://dx.doi.org/10.1016/ j.vaccine.2010.01.008

7. Han N, Adams J, Fang W, Liu SQ, Rayner S. Investigation of the genotype III to genotype I shift in Japanese encephalitis virus and the impact on human cases. Virol Sin. 2015;30:277-89. http://dx.doi.org/10.1007/s12250-015-3621-4

8. Chen YY, Fan YC, Tu WC, Chang RY, Shih CC, Lu IH, et al. Japanese encephalitis virus genotype replacement, Taiwan, 2009-2010. Emerg Infect Dis. 2011;17:2354-6. http://dx.doi.org/ 10.3201/eid1712.110914

9. Huang JH, Lin TH, Teng HJ, Su CL, Tsai KH, Lu LC, et al. Molecular epidemiology of Japanese encephalitis virus, Taiwan. Emerg Infect Dis. 2010;16:876-8. http://dx.doi.org/10.3201/eid1605.091055

10. Beasley DW, Li L, Suderman MT, Guirakhoo F, Trent DW, Monath TP, et al. Protection against Japanese encephalitis virus strains representing four genotypes by passive transfer of sera 
raised against ChimeriVax-JE experimental vaccine. Vaccine. 2004;22:3722-6. http://dx.doi.org/10.1016/j.vaccine.2004.03.027

11. Endy TP, Anderson KB, Nisalak A, Yoon IK, Green S, Rothman AL, et al. Determinants of inapparent and symptomatic dengue infection in a prospective study of primary school children in Kamphaeng Phet, Thailand. PLoS Negl Trop Dis. 2011;5:e975. http://dx.doi.org/10.1371/journal.pntd.0000975

12. Chiou SS, King CC. Japanese encephalitis virus recent infection: detection of IgM antibody. Report of undergraduate student research grant, National Science Council, Taiwan. 1994

13. Chiou SS, Tsai KH, Huang CG, Liao YK, Chen WJ. High antibody prevalence in an unconventional ecosystem is related to circulation of a low-virulent strain of Japanese encephalitis virus. Vaccine. 2007;25:1437-43. http://dx.doi.org/10.1016/j.vaccine.2006.10.044
14. Chiou SS, Crill WD, Chen LK, Chang GJ. Enzyme-linked immunosorbent assays using novel Japanese encephalitis virus antigen improve the accuracy of clinical diagnosis of flavivirus infections. Clin Vaccine Immunol. 2008;15:825-35. http://dx.doi.org/10.1128/CVI.00004-08

15. Wang TE, Lin CY, King CC, Lee WC. Estimating pathogenspecific asymptomatic ratios. Epidemiology. 2010;21:726-8. http://dx.doi.org/10.1097/EDE.0b013e3181e94274

Address for correspondence: Shyan-Song Chiou, Graduate Institute of Microbiology and Public Health, National Chung Hsing University, 250 Kuo Kuang Rd, Taichung 40227, Taiwan; email: sschiou@dragon.nchu.edu.tw

\section{April 2015: Emerging Viruses}

- Reappearance of Chikungunya, Formerly Called Dengue, in the Americas

- Hantavirus Pulmonary Syndrome, Southern Chile, 1995-2012

- Animal-Associated Exposure to Rabies Virus among Travelers, 1997-2012

- Evolution of Ebola Virus Disease from Exotic Infection to Global Health Priority, Liberia, Mid-2014

- Population Structure and Antimicrobial Resistance of Invasive Serotype IV Group B Streptococcus, Toronto, Ontario, Canada

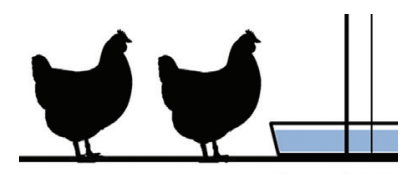

- Sequence Variability and Geographic Distribution of Lassa Virus, Sierra Leone

- Norovirus Genotype Profiles Associated with Foodborne Transmission, 1999-2012

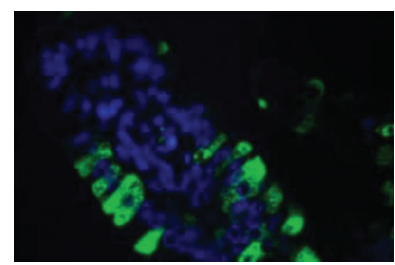

- Deaths Associated with Respiratory Syncytial and Influenza Viruses among Persons $>5$ Years of Age in HIVPrevalent Area, South Africa, 1998-2009

- Influenza A(H7N9) Virus Transmission between Finches and Poultry

- Highly Pathogenic Avian Influenza $\mathrm{A}(\mathrm{H} 5 \mathrm{~N} 1)$ Virus Infection among Workers at Live Bird Markets, Bangladesh, 2009-2010

- Increased Risk for Group B Streptococcus Sepsis in Young Infants Exposed to HIV, Soweto, South Africa, 2004-2008

- La Crosse Virus in Aedes japonicus japonicus Mosquitoes in the Appalachian Region, United States
- Pathogenicity of 2 Porcine

Deltacoronavirus

Strains in

Gnotobiotic Pigs

- Multidrug-Resistant Salmonella enterica Serotype Typhi, Gulf of Guinea Region, Africa

- Reassortant Avian Influenza $\mathrm{A}(\mathrm{H} 9 \mathrm{~N} 2)$ Viruses in Chickens in Retail Poultry Shops, Pakistan, 2009-2010

- Candidate New Rotavirus Species in Sheltered Dogs, Hungary

- Severity of Influenza $\mathrm{A}(\mathrm{H} 1 \mathrm{~N} 1)$ Illness and Emergence of D225G Variant, 2013-14 Influenza Season, Florida, USA

- Close Relationship of Ruminant Pestiviruses and Classical Swine Fever Virus

- Peste des Petits Ruminants Virus in Heilongiiang Province, China, 2014

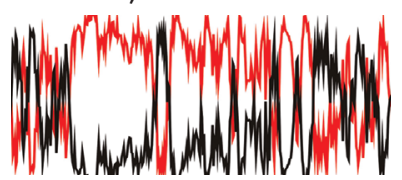

- West Nile Virus Infection Incidence Based on Donated Blood Samples and Neuroinvasive Disease Reports, Northern Texas, USA, 2012

- Influenza A(H10N7) Virus in Dead Harbor Seals, Denmark

- Spotted Fever and Scrub Typhus Bacteria in Patients with Febrile Illness, Kenya

- Virus Antibodies, Israel, 2009-2010

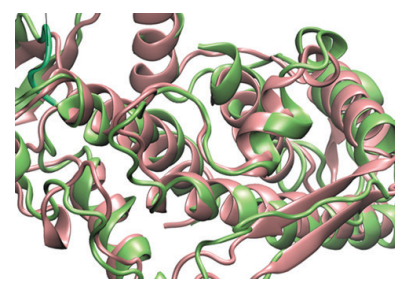

- Outbreak of Severe Zoonotic Vaccinia Virus Infection, Southeastern Brazil

- Lack of Middle East Respiratory Syndrome Coronavirus Transmission from Infected Camels

- Safety of Recombinant VSV-Ebola Virus Vaccine Vector in Pigs 